\title{
The Holistic Management of the Landscape of Ethnic Communities Will Reduce Climate Change and Promote Its Sustainability
}

\author{
Pedro J. Gutiérrez-Yurrita, Andrea Ortega, Adriana Álvarez, Luz A. García, and Minerva Rebollar
}

\begin{abstract}
The Holistic Management of natural heritage is a hot issue in the world today. Correct use that small ethnic groups make of their landscape, depends the life and welfare of the individuals who inhabit the great cities. The concept of holistic management of landscape heritage focuses on providing planning tools to the communities living most conserved natural resources of the planet, precisely because of its ancient exploitation has been marginal and rudimentary. This work takes place in the Hñä-hñu community of Xajay (México). Payments for environmental services might work whether to generate a productive chain of forest conservation, as their mixed forest of oak-pine harvest water, $\mathrm{CO}_{2}$ capture, produces $\mathrm{O}_{2}$ and organic matter and, regulating local climate.A theoretical model of sustainable development for the use of the landscape was developed, which serves to improve the local living standards, mitigate regional climate change, preserving biodiversity and culture of ethnic groups.
\end{abstract}

Index Terms-Conservation of natural heritage, payment for environmental services, sustainable development, theoretical model.

\section{INTRODUCTION}

United Nations has been established that environmental conservation is a priority for the present and future of our planet. Despite of strong economic growth of some countries, billions of people still live far below the poverty line; this is unjustifiable and inacceptable, as Rio +20 concluded last year [1]. The authorities at all times have to foster the wise use of natural resources, in the direction of getting local sustainability. This kind of development must promote social equity, increase the standard of living of rural populations, help eradicate poverty and ensure the constitutional global right that all humans have healthy and favourable environment for their activities. And Xajay is a Mexican ethnic community belonging to the Hñä-hñu group, which should not be excluded from such rights and privileges. Xajay as another hundred of ethnic communities in Mexico is located in a well preserved natural woodland and contains high diversity of natural resources, which if used properly, will promotes a substantial improvement in their standard of living [2]. Holistic management with an ecosistemic approach could lead the locals to transit for getting the dream of sustainability, and all the people in the community and

Manuscript received July 6, 2013; revised October 24, 2013. This work was supported in part by the Research and Graduate Secretariat of the National Polytechnic Institute of México.

Pedro J. Gutiérrez-Yurrita, Andrea Ortega, Adriana Álvarez, Luz A. García, and Minerva Rebollar are with the National Polytechnic Institute of México and Interdisciplinary Center for Research and Studies on Environment and Development, México (e-mail: pgutierrezy@ipn.mx). their associates would raise also their quality of life.

The conservation status of Xajay's natural areas allow them to qualify as of utmost importance to the man, not only because there are extracted the resources to feed the community, but because they provide many environmental services such as climate change mitigation, water harvesting, $\mathrm{O}_{2}$ production, carbon sequestration from atmospheric $\mathrm{CO}_{2}$, retention of soil, slowing local desertification, production of fertile soil and erosion reversal by anthropogenic causes, biological species shelter preserving Mexican biodiversity, by say the most common [3]. These environmental services, are attracting attention in this work, given that so far have not been exploited the benefits of having this with some degree of forest disturbance by Xajay dwellers, and to continue operating as they do in this time, it will end in a few decades. Keep landscape heritage is a right and a duty of Mexican [4]; and therefore, help rural communities get benefits from their rights, using their duty to preserve, at the same time, it is up to our authorities by paying for environmental services.

The sustainable development models developed must be constructed taking into account the interdisciplinary of the concept, which means that the resolution of the model may have different outcomes and results. The basic model generated by economists provides only a natural resource management.That is, when the population grows and need to increase the use of this resource, come to over-exploitation and therefore the model is not sustainable. Usually it is very difficult to construct ecological (mathematical) models simulating complicated ecological processes and natural phenomena. Such models must incorporate many environmental factors as well as social and economic variables, not all of which are describable with required accuracy.

It is noteworthy thatthat each time we use one or another simplified mathematical formulation of a problem, which allows us to describe only a few characteristic features of a process omitting many very important details. However, these primitive models are the basic instruments upon which we started working and eventually have to refine, specifically when we focus on solving multi-causal problems as landscape heritage conservation to move towards sustainability [5].

The aim of this work was to study the territory of the Xajay community under the paradigm of landscape heritage conservation following the approach of holism of the third culture. Special reference is made to the values of the landscape as a provider of environmental services to humanity, through the development of a theoretical model for its management. 


\section{METHODS}

\section{A. Study Area}

Xajay has a population of 488 people, of which 250 are female and 238 are male [6]. Of the economically active population, only $70 \%$ are currently working (115 people: 26 women and 89 men). Jobs and salaries are not stable and often do not reach the minimum wage stipulated by national law, so that approximately $60 \%$ of this population is in multidimensional poverty thresholds. This critical situation of the community, plus the historic social and economic backwardness of the region make that is designated in national statistics as highly marginalized [7]. Xajay (moist soil in native language) is a communal land since 1938, located in the southwestern state of Querétaro in central Mexico. Fig. 1 shows the study area,the community centre coordinates are $99^{\circ} 35^{\prime} 73^{\prime \prime} \mathrm{WL}$ and $20^{\circ} 07^{\prime} 11^{\prime \prime} \mathrm{NL}$.

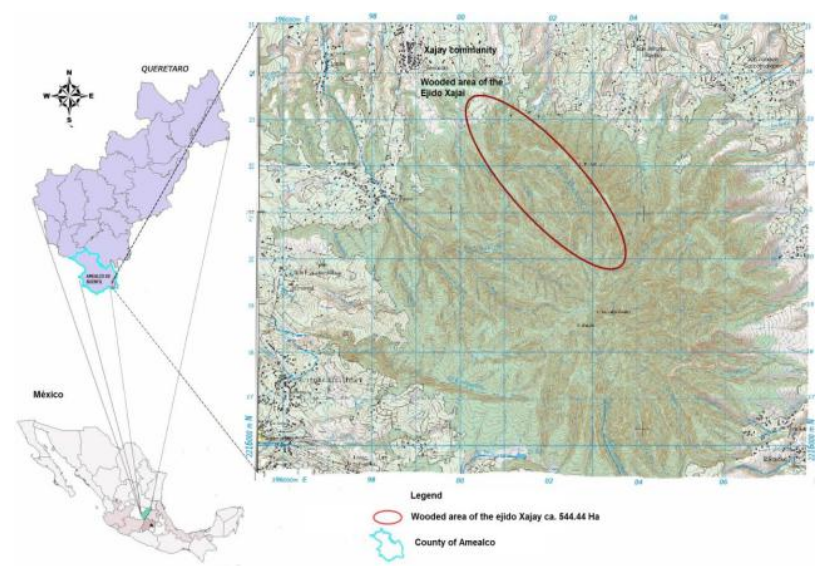

Fig. 1. Location of Xajay community and our study area in the forest well preserved.

The most prominent landscape in lower lands is agro corn parcels (2200 to $2400 \mathrm{~m}$ altitude). The well preserved wooded area belonging to Xajay, ranges from the slopes of the mountain massif El Pelón (2400masl) within the cross Neovolcanic, and consists mainly of a forest where the red oak (Quercus obtusata) and the rough oak (Quercus rugosa) are the dominant species. Other common oaks like Quercus eduardi and Quercus frutex are less abundant but in different altitudinal strata, in the middle of the mountain (about 2700masl), mixed with pines (Pinus oocarpa). At the top of the hills (3100masl) are found some elements of vegetation typical of lower altitudes as the arbutus, ahile, oaks, and many shrubs and many plants form the Compositae family, mixed with proper pasture mountain with little soil. At least three permanent springs are born in this wooded area, two with a very seasonal hydroperiod and the other standing with a minimum flow of $701 \mathrm{~m}^{-1}$. The water is clear, no dissolved solids, with a winter temperature of $17^{\circ} \mathrm{C}, \mathrm{pH} 6.8$, leads to various productive activities such as aquaculture or to irrigate fields of vegetables. Can also be made tourist activities in this region, spa type, ecotourism, and rural tourism and has been recently proposed, responsible tourism [8].

\section{B. Fieldwork}

Four routes through the forest area of Xajay to delimit the area with more vegetation and better condition were conducted from October to June (2012-2013). We also determined the dominant plants. The vegetation covers maps, including altitudinal gradients and topography of the land to estimate vegetation cover were developed using ArcView GIS and satellite photos. Finally, we integrate the information gathered to estimate the ecological value of the forest to propose a scheme of payments for environmental services to the community authorities.

\section{Conceptual Framework for Sustainable Development}

Sustainable development is a concept of the economy that has been poorly adapted to conservation biology and therefore social results are disastrous [9]. However, as a theory, it is not badly posed, so we picked it up to move towards a model that leads us to local sustainability, especially when resources are used marginally by high economically backward communities, but with a great natural and cultural capital. Based on the theory of classical quantitative ecology, we developed a model that helps to estimate the speed at which natural resources should be exploited. And through some adjustments in the model, derived from the theory of resource competition of several species in the same habitat, and habitat saturation, we have got an equation that can have multiple endings, and thus minimize the effect load capacity and the concept of maximum utilization of resources in an ecosystem. The generated model is contrasted with actual field data of an ethnic community to establish what may be the end of the same variables, so that once quantified each of the variables (ecological, economic and social) can be planned holistically landscape management of Xajay.

\section{RESUltS}

The people of the ethnic community of Xajay, belonging to a highly marginalized population that presents unequal opportunities and, is found in disadvantaged situations to be mostly indigenous language speakers and though some speak Spanish they only have access to the basic education.

This situation has led people to migrate to the capital city of the state of Queretaro, the City of Mexico or to the United States as labourers or bricklayers. Today almost $80 \%$ who are international migrants have returned and are employed as bricklayers and stonemasons in the aforementioned cities of Mexico, because of the American economical crisis since 2010.

Lack of opportunities due to ignorance in the economic and education, and having an indigenous language as their first language, to name the most representative, have been limiting in Xajay in entering the labour market and have better opportunities in life. Also, this reality has forced to emigrate and leave their natural resources. Abandoned land soon becomes in wasteland with little soil, terrain with high erosion and desertification, undermining the natural wealth of the landscape. Abandon old farmland is a disadvantage for the community against other communities when they apply for government support, and even the program can be left out of environmental services of the forest or hydrological environmental services.

The wooded area of Xajay's mid-mountain is the best preserved of its territory. The forest can be aged between 60 and 100 years since it was severely cut in the early twentieth century to the railway sleepers (Fig. 2). Older trees can be 
found, but they are isolated. Forest resources are utilized more firewood either logging or cutting its branches. The fertile soil layer does not exceed $0.5 \mathrm{~m}$ thick and relentless action of wind and water flow toward the trailing lowlands. Plant species most used are the oaks and pines, but also used the berries and fruits of many herbaceous. The medicinal properties of the understory are well known and are used only for the local population.

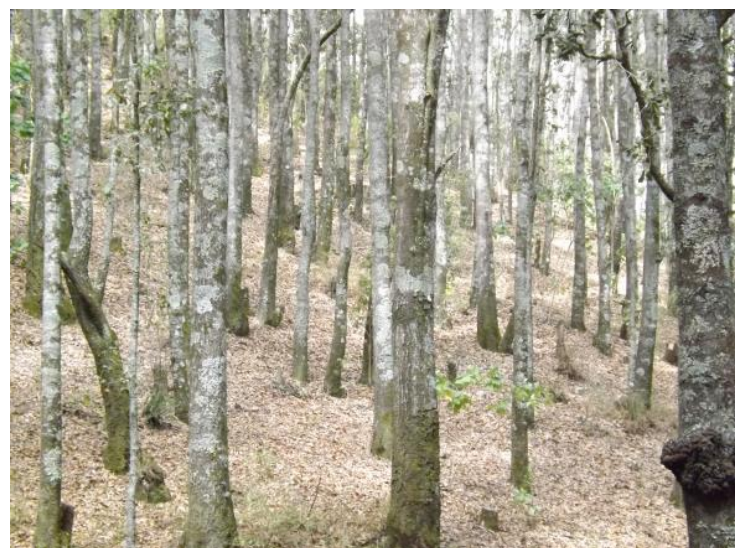

Fig. 2. View of young oaks planted in the reforestation of the fifties (winter time February, 2013).

The type of forest, temperate climate with summer rains, and the paths through the wooded area are favourable for the development of low-impact productive activities in nature, but profitable to tenants. Similarly, the density of the forest and its conservation status favourable do provide environmental services of various kinds. Because about $20 \%$ of the working population of the community is inactive, which contributes to accentuate the degree of marginalization in which it operates. However, these people are in a position to initiate a project to take care of their natural resources. And they are working with forest rehabilitation programs to be proposed in the Environmental Services Payment. An important aspect to consider in the PFES for scenic beauty is that landscape preservation allows to people to sell several other environmental services, such as those listed above. Fig. 3 shows that the vegetation of the mountain of Xajay exceeds 500ha (mixed forest of pine-oak $=445.03 \mathrm{ha}+$ mixed forest of oak-pine $=84.89 \mathrm{ha}$ ). Therefor, Federal authority and NGO can pay for maintaining a 500 ha plant coverage up to $\$ 20,000$ USD in Xajay. This payment will be covered in five years, with annual payments of $\$ 4,000$ USD.

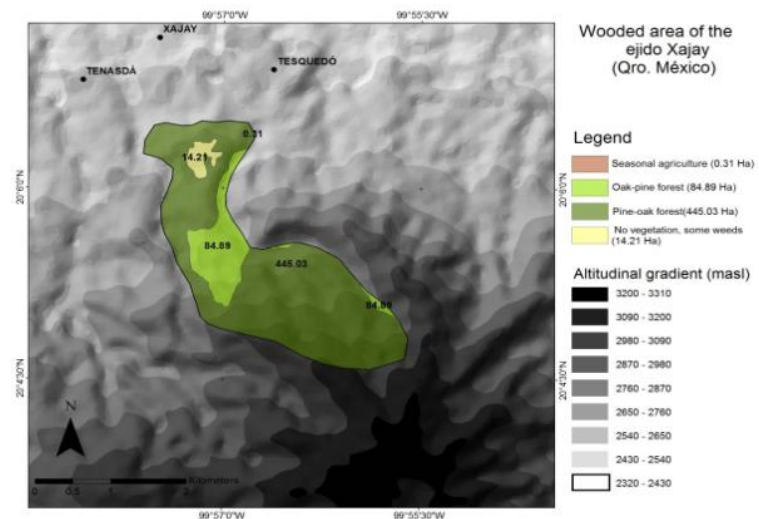

Fig. 3. GIS Estimated Xajay's wooded area. The pine-oak forest stands out for its extension; however, the oak-pine forest also has many other ecosystemic values.
The high variety of tree species and understory plants studied led us to perform a theoretical model of how the community can reach sustainable development, using a variety of ways his mountain. In this way, the community will begin to understand that the physical structure and ecological functions of the landscape is its greatest asset and to take care of is worth. Three basic premises are the pillars of the model developed:

1) There is a limit to the carrying capacity of ecosystems.

2) The loading capacity of a system isa function of the initial number of individuals begins to populate the system or use the resources.

3) There is a natural limit to food production in each ecosystem.

Under these assumptions, we can say that the closer the use of nature to the maximum capacity of resource utilization, less potential for growth (economic and population) there are that system. Fig. 4 shows a graph would be of this type. In addition, specific considerations arising from the same model resource consumption, $\mathrm{R}[\mathrm{C}]$, is a function of the maximum possible amount of a resource, Rmax, less resource loss from any cause that may reduce their availability or amount, in short, their access to him, Z[C].An interesting aspect of the proposed model plotted in Fig. 4 is that when the bisector cut the $\mathrm{x}$-axis, there should no be growth. In other words, when the sloping line reaches the point where $\mathrm{K}$ is marked (maximum of available resources), there should be no economic growth, because that would be an over-exploitation of resources and would not be sustainable growth.

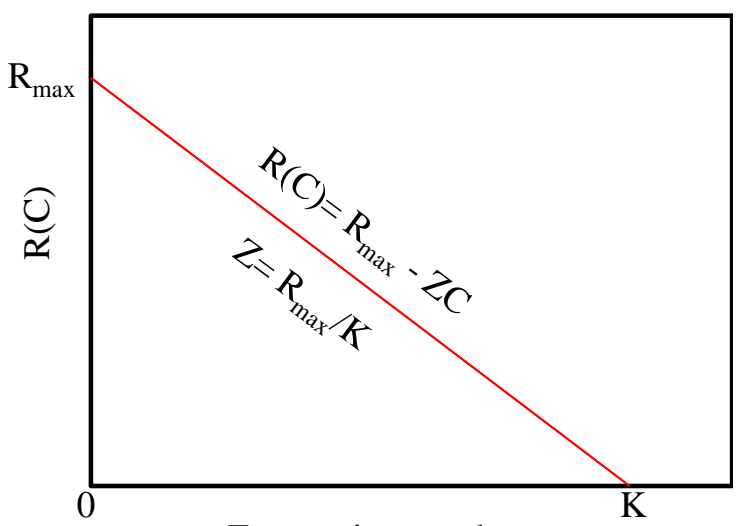

Economic growth

Fig. 4. Relationship betweenthe use of natural resourcesandthe economic growth. Critical points of sustainable development are marked: K: Maximum capacity of natural resource use; $\mathrm{R}_{\max }$ : Maximum capacity of natural resources. Z: availability of natural resources. Note that the degree of inclination of the line $\mathrm{R}[\mathrm{C}]$ is crucial for achieving sustainable development. A highly inclined line represents a resource utilization without reaching the maximum capacity available, since it would cut the $\mathrm{x}$ axis before reaching $\mathrm{K}$, while a slightly pronounced straight, when it comes to economic growth axis, can exceed the maximum resource availability [K].

However, model showed in Fig. 4 alone does not lead to any population sustainability, and that taking into account that the same population is also growing in number of individuals, and that new heads of families should use the resources of the same landscape heritage, adjustments are needed in the model.

Adjustments to the model, first taking into account the ecosystems that make up the landscape of Xajay; were subsequently analysed the structure and functioning of each ecosystem and how it relates to other ecosystems, and third, 
were taken into consideration the practices and customs of the locals. In this way, we have the elements to handle them holistically in a new theoretical model of sustainable development.

The mathematical formulation should contain two key elements: the economic growth is exponential $\left[C_{t}=C_{0} e^{R T}\right]$, but natural resources are limited $[1-(C / K)]$. So the faster growing, fewer resourcesare available for use. And combining elements of the economy (development) with the ecology (carrying capacity) in an inverse relationship we have that the greater the growth, the smaller the resource that can be used. These variables can be handled simultaneously with a logistic model like the showed in Fig. 5.

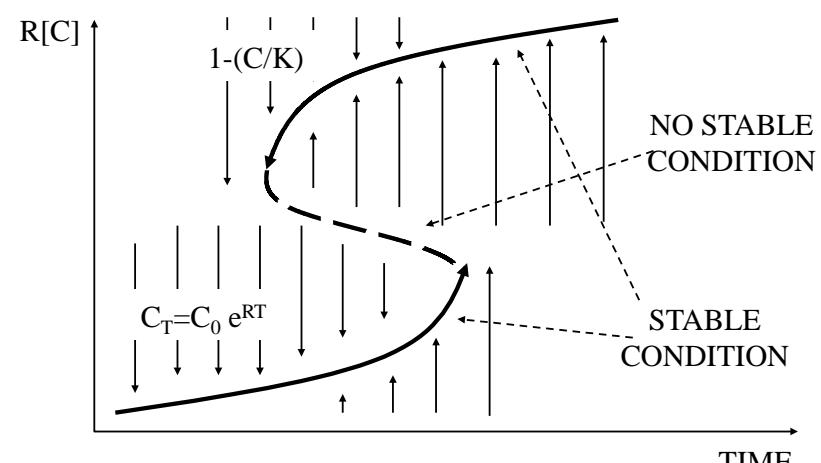

Fig. 5. Hypothetical curves generated by the logistic model applied to economic growth would experience a population in time with respect to the availability of resources. It should be noted it has a non-stable growth phase, where a small change in the production rate in the population or in the magnitude of environmental factors can produce a qualitative leap in the system (inflection point of the curve). From that moment, begins to be a limit to growth, which may be given by the availability of the resource under exploitation or competition between individuals of the same population for the same resource in quantity and access.

When economic growth begins no restrictions, resources seem unlimited, so that growth is shaped exponential curve (Fig. 5). Growth, therefore, is determined by the initial population size and the amount of resources under exploitation [Capital $=$ Working Capital + natural capital $]$. When is reached in either case to a growth limit decreases and stabilizes at a horizontal, end of the curve and second part of the model.

The equations describing the function graphed in Fig. 4 are well known by ecologists, so they can be easily applied to the green economy issues. The first part of the mathematical function $\left[C_{t}=C_{0} e^{R T}\right]$ is known analytical form [exponential function] and indicates that economic growth $R[C]$ of the population at time $[t]$ is a function of the initial capital multiplied by number $e(2.718 \ldots)$ raised to the power $R T$, where $R$ is the growth rate of the population using resources. Populations are rarely found in optimal conditions to its environment (availability of resources) to unlimited economic growth, therefore, based on the exponential population growth equation: $\left.C_{t}=C_{t}-1+d_{C} / d_{t}\right]$, and introducing a variable or magnitude that limits growth $[K]$, we have: $d_{C} / d_{t}=r C[(1-(C / K)]$, which would be resolved as follows: $C_{t}=C_{0} * K / C_{0}+\left(K-\mathrm{C}_{0}\right) e^{-R T}$. $[K]$ is the constraint as it directly affects $R[C]$ (i.e., the net rate of growth, and if this rate is zero because it is in the maximum exploitation of a resource $R=0$, then $C$ would also be zero because any number (magnitude) multiplied by zero is zero).

Now, to make this model a model of sustainable development, it should be easy to diversify the products obtained from the landscape, so that there should not be a limit of carrying capacity $[K]$, but several outputs production of the same landscape $\left(C_{1}, C_{2}, C_{3} \ldots\right)$. In such a way that the final model is opened to more possibilities, not only the local population uses resources have a single resource for economic growth, but can have many more resources. The final composite equation can be something like the one shown below:

$$
d_{c} / d_{t}=r C-\left(r / K-N^{2}\right)-\chi C_{1} C_{2}
$$

where $d_{C} / d_{t}$ is the rate of economic growth over time; $r C$ if growth is unlimited; $r / K-N^{2}$ is the limit for growth or economic growth dependence on the availability of resources and the effect $\chi C_{1} C_{2} \ldots$ to have more of a chance to maintain growth resources (if the value of $\chi$ is positive). Or on the other hand, is the effect of competition for a limited resource access (if the value of $\chi$ is negative) (Fig. 6).

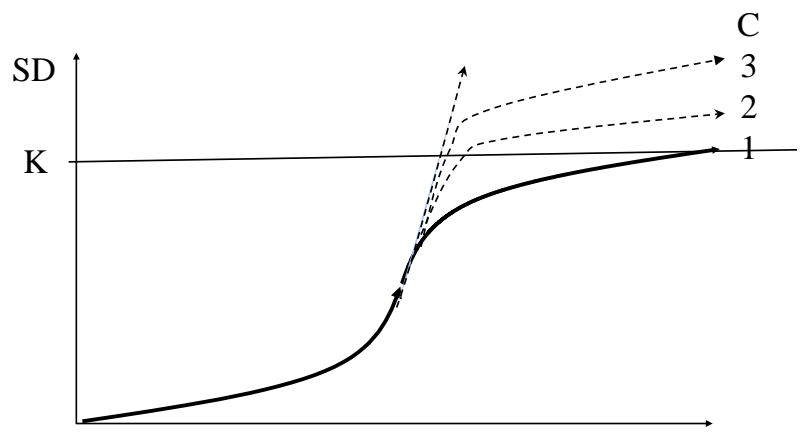

TIME

Fig. 6. Theoretical representation of sustainable development that combines ecological and economic concepts to generate social welfare and economic growth, without producing great environmental impact and fast depletion of natural resources. The $K$ at the figure is just to remember the $K$ of the previous figure, but has no meaning in the adjusted model, because there is no predetermined limit to the activities, provided that they are diversified $(C)$. In this way, $C$ can be developed with various activities sustainability criteria in this case are exemplified threefold: $1,2,3$.

\section{DISCUSSION}

The Mexican constitution states, since October 2003, that everyone has the right to enjoy a favourable environmental to their health, welfare and activities. This human right of latest generation originated the national development agenda of the country. By this way, it is clear that it is a national priority environmental conservation and that development of the country will be under the paradigm of sustainability. It has the slogan that the country cannot grow without caring their natural resources and for that purpose; we must halt and reverse environmental degradation accumulated. This is a priority for national security. Thus, the National Forestry Program from its beginning in 2001, stated in section 3.9 that México has great potential to benefit the environmental services market. And in terms of Mexican law establishes the Mexican Forest Fund as an instrument to promote conservation, growth, sustainable use and restoration of forest resources and their associated resources providing, among others, access to financial services in the market, promoting projects that contribute to the integration and competitiveness of the productive chain, and developing 
mechanisms for collection and payment of goods and environmental services. Importantly, the "Covenant by Mexico", held by major political forces in Mexico, due to the entrance of the new government, in 2012, set out in section 2.8 transform the field in a more productive activity that the agreement 66 refers to strengthen Payment for Environmental Services of the Forest in all its aspects [10].

The holistic way of understanding the relationship between man and nature is not new, of course, but the point of view in our time making itself makes it new, to a degree that may be the paradigm of our era, and the basis for the design of our world future. We are in the holism of the third culture [11]. The problems that arise in natural resources and are facing the residents of the Xajay community, interest in taking some measures to halt the deterioration of them and help restore the landscape that had once, it becomes a niche opportunity to propose projects management that lead them to take actions that ecologically rehabilitate the forest system; and in the medium and long term, increase water harvesting, capture $\mathrm{CO}_{2}$ and produce $\mathrm{O}_{2}$ and organic matter production, that contribute to soil fertility and local climate regulation. However, not covered by these projects in their neighbourhood improvements, more urban services, buildings, etc. because the growth of the urban area of the region should be at the expense of agricultural land or well preserved forest.

Mexican environmental public policy explicitly recognizes the importance of the environmental services provided by forests to productive activities and consumption, among which are the conservation of biodiversity, the maintenance of the pool of genetic resources, atmospheric carbon sequestration, to mitigate climate change, attracting landscape tourism and ecotourism, and protection of hydro graphic basins, disaster reduction and aquifer recharge. And there is a desire by authority to promote their protection and encourage the maintenance of its production through a strategy of generating environmental services markets.

The National Forestry Commission in conjunction with the National Institute of Ecology and Climate Change are the institutions responsible for promoting, encouraging, review applications and determine payments for environmental services. As a first instance, since 2003 have payments for forest environmental services (PFES) that favour water infiltration, called Hydrological Environmental Services. \$60million USD from the payment of water rights to 271 owners of 127,000ha of temperate forests, jungles and cloud forest, which is approximately $\$ 0.15 \mathrm{USD} / \mathrm{ha}$, has been allocated for the period 2003-2005 PFES. Given the insufficient resources to continue and expand the program, it was designed a local modality now also support local governments funded the program for certain strategic areas for the conservation of biodiversity.

The new program of environmental services in the form used as a reference hydrological basins and aquifers reviews overexploited, and the relevance of water sources for villages over 5,000 population that could eventually take control of the environmental service payments through their own local governments and / or drinking water operating agencies. With a commitment to a minimum canopy cover of $80 \%$ over the five-year term of the agreement, makes an annual payment of $\$ 30 \mathrm{USD} / \mathrm{ha}$ temperate forests and jungles and
\$40USD/ha. in the case of cloud forest. PFES programs for Carbon Capture and Diversity conservation and scenic beauty are recently established by the methods for measuring carbon sequestration and its impact on climate change mitigation. Carbon sequestration be quantified by capturing $\mathrm{CO}_{2}$ from plants, and would be paid between \$5-5.5USD / ton $\mathrm{CO}_{2}$ captured. As regards the price of the landscape, nothing is written yet, but the trend is to use the methods of ecological economics as the hedonic price and contingent value, widely used in studies of ecotourism and management of protected areas. Finally, biodiversity may be paid considering a differential value and weight of each species according to their ecological status, for example, pays more an area with endangered species, an area with generalist species, with populations rapidly and marked growth.

Management with holistic approach, comprehensively considers all dimensions involved in it: i) the quantity and quality of natural resources; ii) the needs of the population; iii) the situation in which they find resources; iv) the population is willing to participate in the project; $v$ ) the vision that community has concerning the landscape in many different approaches: economic, spiritual; and vi) the general state of the ecosystems that host resources, if resources are underachievement or if they are suitable for environmental services. This management, applied in an organized, accompanied by training and a program developed in detail would enable people in the community to manage federal institutions for payment for environmental services [10]. Only by this way, their wooded area will contribute to climate change mitigation will generate benefit for them and for their landscape.

However, uncoordinated policies of local governments of Mexico (State and Municipal respect with federal policies), especially when they are trying to integrate with neoliberal trade policies. This form of globalization brings serious social harm in ethnic communities, beginning with the concentration of land in the hands of a few international corporations. One of the fatal consequences is the growing exodus of rural people to the cities. The most serious immediate social consequence is the loss of small property, the heritage of local people, the loss of communal lands, and the loss of peasant and indigenous identity and uprooting. In brief, involuntary exile hopeless of return [12]. The small family of yesteryear, contributed substantially to social and territorial balance by allowing countries to maintain the demographic balance between rural and urban populations, as well as human capital and territorial. On the other hand, helped to maintain environmental quality higher than that imposed by aggressive production schemes, capital from foreign currency for the purpose of exploiting the natural resources of the nation disjointed.The most immediate environmental impact of this social and economic disaster is the climate change. Weather change begins with local small changes. These small changes are already in the knowledge of the local communities. They often tell us that not raining now as 50 years ago, that heat and cold are more intense every year; the seasons do not correspond as before and find it harder to know when to plant. And in a secondary impact, loss of wooded area accelerates regional climate change affecting cities in their energy balances. A city must invest more energy in heating and air conditioning. 
At present, many environmental services were found in Xajay's wooden lands, such as:

- Climate change mitigation

- Maintaining the capacity of recharge aquifers,

- The maintenance of the water quality,

- Reduced downstream sediment load,

- Reduced flows during extreme rainfall events,

- The conservation of springs,

- The largest volume of surface water available in the dry season and

- Reducing the risk of flooding

- Carbon Sequestration

- Oxygen production

- Landscaping, scenic contemplation, spiritual rest and recreation.

Each of these environmental services is one of the C's in the theoretical model (Eq. 1), so that the population growth can be paired with economic growth of the community through planned diversification of landscape heritage resources. The model constructed to estimate the rate at which we use renewable natural resources should not exceed the recovery rate of the resource under exploitation ( $\mathrm{K}$ of the Fig. 4). But it must also be noted that as a model, is just a simplification of reality, and when a resource is used, modified other environmental factors, so it is difficult to make an accurate prediction of how the resource will respond under certain intensity of use, or what might be its resilience under prolonged use. Fig. 7 shows the territory of the community of Xajay, where can be appreciated that aesthetic, ecological and cultural values of the landscape are networked.

Sustainability model is playing with complex systems networked. So when it achieves a holistic management of the natural heritage, that is, of many units that make up a system, is possible to maintain the balance of the ecological functions that cross its operating limits [13]. Maintaining natural resources, promotes gas exchange prevents atmospheric greenhouse effect, especially when located near large urban centres, provides rural and metropolitan society, several environmental services essential for the survival of the human species, reduce the radicalization of the weather, mitigating climate change and conserving biological diversity.Caring Xajay forest could help mitigate weather radicalization, local and regional [3]. Any economic activity, by definition, is a form of nature management [11].

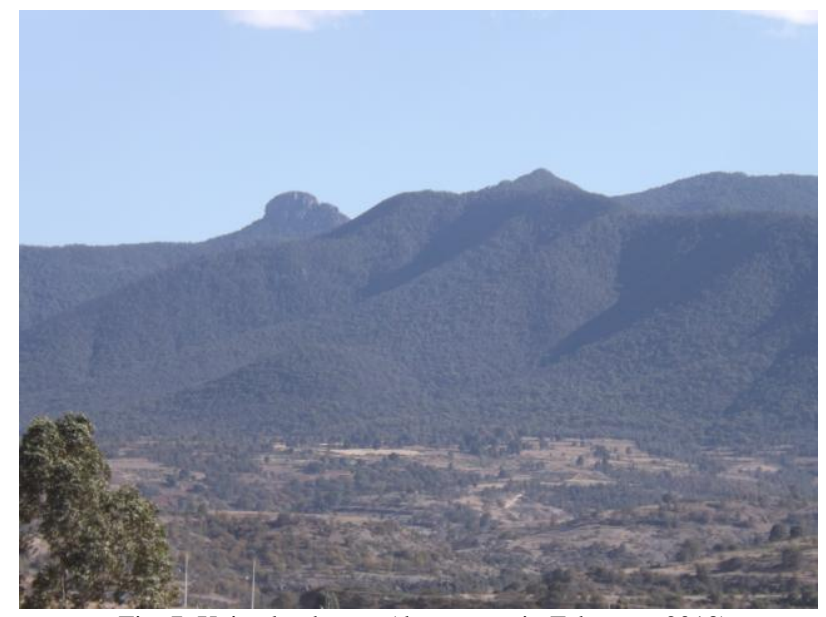

Fig. 7. Xajay landscape (dry season in February, 2013).

\section{CONCLUSIONS}

Clearly, public administration acts in good faith with the program of payments for environmental services, with a real interest in conservation; however, the same law states that they should generate a market of independent PES government. This implies that there must be sellers and buyers (intermediaries maybe). At the moment, the sellers are the farmers and peasants, while buyers are the government in Mexico. But what happens when the government stops subsidizing a public good of the nation? It is assumed that there must be private buyers, which means that the values of ecosystems will be priced in the goods market. Will price in the stock market, the forest will give us oxygen and mitigate climate change? How much money will have to regulate environmental markets, which are essential to human life, as we know the NGOs? These questions arise because Xajay community owns forestlands, for current and ancestral rights. But now that the greatest concentration of people in cities lies, depends on the peoples living in the mountains take care of their natural resources for our survival. And how to explain that peasants must sacrifice their well-being in terms of modern satisfactions, to maintain and improve the quality of life of the urban population? Is it a social injustice or ecological injustice, or both?

Many answers to questions can be raised, but all means, necessarily for resolution, to an interdisciplinary, team, horizontal, audacious and, sometimes even reckless [2]. Centuries ago the Greeks called this form of transdisciplinar work but reductionist: Consilience. And today, perhaps more than before, the concept is gaining strength. But as a concept of total integration. Without falling into the trap of scientific reductionism. This new vision has been called holism in a little over a century [12]. The holistic way of understanding the relationship between man and nature is not new, of course, but the point of view in our time making itself makes it new, to a degree that may be the paradigm of our era, and the basis for the design of our world future. We are in the holism of the third culture [11]. Our-world culture [14]. The culture that makes us both different and equal to others at the same time. We try to keep us free, but we were born in series and in the end, act like everyone else, and no matter the country or the economic level of the people.

The problems that arise in natural resources and are facing the residents of the Xajay community, interest in taking some measures to halt the deterioration of them and help restore the landscape that had once, it becomes a niche opportunity to propose projects management that lead them to take actions that ecologically rehabilitate the forest system and the river; and in the medium and long term, increase water harvesting, capture $\mathrm{CO}_{2}$ and produce $\mathrm{O}_{2}$ and organic matter production, that contribute to soil fertility and local climate regulation. However, not covered by these projects in their neighbourhood improvements, more urban services, buildings, etc. because the growth of the urban area of the region should be at the expense of agricultural land or forest

To achieve the objectives of this work, will generate wealth locally, will help raise the standard of living of the community and achieve their cultural goals (religion, education, traditional festivals). The model of sustainable development with a holistic approach, suggests it could only have sustainable development, in the sense defined by 
national and international law, if the end products are diversified in a human community, which uses natural resources or environmental uses within the same ecosystem and not exceeded in all productive or extractive supply resilience of the system [13].

\section{ACKNOWLEDGMENT}

We thank the authorities of the Municipality of Amealco (Querétaro, México) and to the delegates of Xajay community and, its people for the facilities that we got to do fieldwork.This project is sponsored by the National Polytechnic Institute under projects SIP-20121781 and SIP-20131377 (Managing rural landscape under the holistic ecosystem approach). Andrea Ortega and Adriana Alvarez were fellows PIFI program.

\section{REFERENCES}

[1] P. J. Gutiérrez-Yurrita, "Ladnscape ecology, today: And I laugh, laugh I really laugh," Serendipia, vol. IV, no. 25, pp. 58, July 2013.

[2] P. J. Gutiérrez-Yurrita. "Nature holistic management," in Environment, Society and Environmental Policy in México: An Interdisciplinary view, E. Campuzano and M. L. Valderrábano (Comp.), Eds. México: Editorial Porrua-IPN, 2011, pp. 9-40.

[3] P. J. Gutiérrez-Yurrita, "Global climate change effectson biodiversity," Derecho Ambiental y Ecología, vol. 4, no. 20, pp. 61-70, 2007.

[4] P. J. Gutiérrez-Yurrita and M. Á. López-Flores, "Law and Environmental thoughts on natural protected áreas. A proposal of a new international category: Metaphysic space (spiritual space)," Revista Aranzadi de Derecho Ambiental, vol. 20, no. 2, pp. 19-42, 2011.

[5] J. S. Román, L. Marín-García, P. Muñoz, M. A. López, and P. J. Gutiérrez-Yurrita, "Ecological considerations for the management of a protected area with a strong urban pressure: the case of Lake Texcoco, México," International Journal of Ecology and Environmental Sciences, vol. 39, no. 1, pp. 26-37, 2013.
[6] INEGI, XIII Population and Housing Census: Querétaro, México: Instituto Nacional de Geografía y Estadística, 2010, pp. 300.

[7] CONAPO, Marginalization Index by Locality, México: Comisión Nacional de Población, 2010, pp. 290.

[8] A. Álvarez, N. Zamora, and P. J. Gutiérrez-Yurrita, "Proposal of a new model of tourism in natural protected áreas: responsable tourism," in Proc. $1^{\text {st }}$ International Symposium of Innovation in Industrial and Environmental Systems, México D.F., 2013, pp. 55-61.

[9] P. J. Gutiérrez-Yurrita, "The Sustainable development viewed by an ecologist: myths, controversies and future (first part)," Derecho Ambiental y Ecología, vol. 29, no. 5, pp. 65-81, 2009.

[10] CONAFOR Comisión Nacional Forestal. [Online]. Available: http://www.conafor.gob.mx/portal/index.php/tramites-y-servicios/apo yos/mecanismos-locales-de-pago-por-servicios-ambientales-a-travesde-fondos-concurrentes visited on 05-03-2013

[11] P. J. Gutiérrez-Yurrita, "To design the future! The holism of the third culture [to the scientific integration and humanities]," México: Instituto Politécnico Nacional-Centro de Estudios Jurídicos y Ambientales, 2009, pp. 250

[12] J. C. Smuts, Holism and Evolution, USA: The Gestalt Journal Press, 1966, pp. 240

[13] P. J. Gutiérrez-Yurrita, "The Sustainable development viewed by an ecologist: myths, controversies and future (third part)," Derecho Ambiental y Ecología, vol. 31, no. 5, pp. 59-65, 2009.

[14] G. Lipovetsky and J. Serroy, "The world-culture," España: Anagrama, 2010, pp. 213

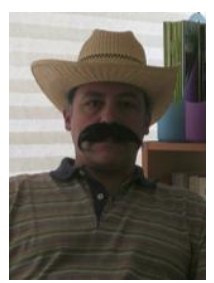

Pedro Joaquín Gutiérrez-Yurrita studied biology and got a Master in Sciences with a specialty in systems biology and resource management, a Ph.D. in Biological Sciences with speciality in Ecology. After that, he studied another Master in Sciences but in Sustainable Development and Environmental law. And finally he has another doctorate, that time in Environmental Law.

Over the past $30 \mathrm{yrs}$, he has devoted to the study of the ecology under the ecosystem approach. He has conducted over 30 scientific researches in Wetland Conservation, and trying to mitigate the environmental impacts produced by exotic species and by overexploiting biotic resources in natural protected areas. He introduces himself in the field of the environmental law and ecological economics 15 yrs. ago. It is not possible biological conservation without better laws. 